\title{
The Role of Core Needle Biopsy for the Evaluation of Thyroid Nodules with Suspicious Ultrasound Features
}

\author{
Sae Rom Chung ${ }^{1}$, Jung Hwan Baek, MD, $\mathrm{PhD}^{1}$, Young Jun Choi, $\mathrm{PhD}^{1}$, Tae-Yon Sung, $\mathrm{PhD}^{2}$, \\ Dong Eun Song, $\mathrm{PhD}^{3}$, Tae Yong Kim, $\mathrm{PhD}^{4}$, Jeong Hyun Lee, $\mathrm{PhD}^{1}$ \\ Departments of ${ }^{1}$ Radiology and Research Institute of Radiology, ${ }^{2}$ Surgery, ${ }^{3}$ Pathology, and ${ }^{4}$ Endocrinology and Metabolism, University of Ulsan \\ College of Medicine, Asan Medical Center, Seoul, Korea
}

Objective: Recent studies demonstrated that core needle biopsy (CNB) can effectively reduce the possibility of inconclusive results and prevent unnecessary diagnostic surgery. However, the effectiveness of CNB in patients with suspicious thyroid nodules has not been fully evaluated. This prospective study aimed to determine the potential of CNB to assess thyroid nodules with suspicious ultrasound (US) features.

Materials and Methods: Patients undergoing CNB for thyroid nodules with suspicious features on US were enrolled between May and August 2016. Diagnostic performance and the incidence of non-diagnostic results, inconclusive results, conclusive results, malignancy, unnecessary surgery, and complications were analyzed. Subgroup analysis according to nodule size was performed. The risk factors associated with inconclusive results were evaluated using multivariate logistic regression analysis.

Results: A total of 93 patients (102 thyroid nodules) were evaluated. All samples obtained from CNB were adequate for diagnosis. Inconclusive results were seen in $12.7 \%$ of cases. The diagnostic accuracy, sensitivity, specificity, positive predictive value, and negative predictive value for diagnosis of malignancy were $93.8 \%, 100 \%, 100 \%, 78.9 \%$, and $95 \%$, respectively. None of the patients underwent unnecessary surgery. The diagnostic performance was not significantly different according to nodule size. On multivariate logistic regression analysis, larger nodule size and shorter needle length were independent risk factors associated with inconclusive results.

Conclusion: Samples obtained by CNB were sufficient for diagnosis in all cases and resulted in high diagnostic values and conclusive results in the evaluation of suspicious thyroid nodules. These findings indicated that CNB is a promising diagnostic tool for suspicious thyroid nodules.

Keywords: Thyroid nodule; Core needle biopsy; Fine needle aspiration; Ultrasonography; Suspicious nodule

\section{INTRODUCTION}

Ultrasound (US)-guided fine needle aspiration (FNA) is generally considered to be the gold standard for the diagnosis of thyroid nodules due to its simplicity, safety,

Received February 13, 2018; accepted after revision April 3, 2018. Corresponding author: Jung Hwan Baek, MD, PhD, Department of Radiology and Research Institute of Radiology, University of Ulsan College of Medicine, Asan Medical Center, 88 Olympic-ro 43-gil, Songpa-gu, Seoul 05505, Korea.

- Tel: (822) 3010-4348 • Fax: (822) 476-0090

- E-mail: radbaek@naver.com

This is an Open Access article distributed under the terms of the Creative Commons Attribution Non-Commercial License (https://creativecommons.org/licenses/by-nc/4.0) which permits unrestricted non-commercial use, distribution, and reproduction in any medium, provided the original work is properly cited. cost-effectiveness, and diagnostic accuracy (1). Studies report a diagnostic sensitivity of $83-98 \%$ and specificity of $70-92 \%(1,2)$. However, the key disadvantage of FNA is the high rate of non-diagnostic and indeterminate cytology results, including atypia of undetermined significance (AUS) and follicular lesion of undetermined significance (FLUS), which occur in approximately $10-33.6 \%$ and $15-42 \%$ of all FNA samples, respectively (3-6). In addition, many studies indicate that the false-negative rate of FNA cytology with respect to thyroid cancers is insignificant; studies show the estimated malignancy rate of nodules with benign cytological results to be $3.7 \%$ (7) and 1-2\% based on repeat FNA results or long-term follow-up (8-10). However, thyroid nodules that were benign on FNA cytology but had suspicious features on US had a higher false-negative rate 
of $13.6-56.6 \%(9,11-17)$.

To overcome the limitations of FNA, core needle biopsy (CNB) has been suggested as an alternative technique (18-20). Studies have established CNB as a feasible, safe, and well-tolerated technique that is associated with a low incidence of complications (21-23). Several recent studies demonstrated that CNB can effectively reduce the possibility of inconclusive results (22-24) and prevent unnecessary and/or diagnostic surgery $(22,23,25,26)$. However, the role of CNB for the assessment of thyroid nodules with suspicious US features has not been well established. One study evaluated the malignancy risk of suspicious thyroid nodules that exhibited benign results on CNB (27). The study showed that CNB had a lower false-negative rate of $3.6-5.5 \%$ according to various US risk systems. However, the study design was retrospective and focused only on the false-negative rate of CNB. Therefore, the effectiveness and safety of CNB for suspicious thyroid nodules requires further evaluation, and this prospective study was designed to determine the potential merit of using CNB to assess thyroid nodules with suspicious US features.

\section{MATERIALS AND METHODS}

\section{Study Population}

The protocol for this prospective study was approved by the local Institutional Review Board. Consecutive adult patients (aged $\geq 18$ years) who underwent US-guided CNB for thyroid nodules between May and August 2016 and who had at least one suspicious feature on US were enrolled in the study (28). Informed consent was provided by all patients.

\section{US-Guided CNB}

Ultrasound examination was performed using one of three systems: an iU22 or HDI-5000 unit (Philips Healthcare, Bothell, WA, USA), or an EUB-7500 unit (Hitachi Medical Systems, Tokyo, Japan). Each was equipped with a linear high-frequency probe (5-14 MHz). All US examinations and US-guided CNBs were performed by one of five radiologists supervised by two faculty radiologists with 21 years and 14 years of clinical experience in performing and evaluating thyroid US examinations, respectively.

Ultrasound-guided CNB was performed using a disposable 1.1- or 1.6-cm excursion, 18-gauge double action springactivated needle (TSK Ace-cut; Create Medic, Yokohama, Japan) following local anesthesia with $2 \%$ lidocaine (23,
26). Using a freehand technique, the core needle was advanced from the isthmus of the thyroid towards the nodule. After the tip of the needle had been advanced into the edge of the nodule, the distance of fire $(1.1 \mathrm{~cm}$ or 1.6 $\mathrm{cm}$ ) was measured before sequential firing of the stylet and cutting cannula of the needle. After applying firm local compression to the biopsy site for 10-20 minutes, patients underwent an observation period. If the patients complained of pain or neck swelling, US examination was repeated to evaluate complications (29).

\section{Analysis of US Findings}

In all patients, US examination was performed prior to CNB by one of the five radiologists under the supervision of the two faculty radiologists. Nodules were evaluated for the following features: internal composition (solid, predominantly solid, predominantly cystic, or cystic), shape (ovoid-to-round, taller-than-wide, or irregular), margin (smooth, spiculated, or ill-defined), echogenicity (isoechoic, hypoechoic, markedly hypoechoic, or hyperechoic), and the presence of microcalcification, macrocalcification, or rim calcification. Nodules with suspicious features on US examination were defined as those having at least one of following features: marked hypoechogenicity, microcalcification, spiculated margin, or taller-than-wide shape (28).

\section{Analysis of CNB Histopathology}

Core needle biopsy and surgical specimens were reviewed by a staff pathologist with 13 years' experience of thyroid cytopathology. CNB results were categorized into six categories according to guidelines from the Korean Endocrine Pathology Thyroid Core Needle Biopsy Study Group (30). A non-diagnostic CNB reading (category I) included specimens with an insufficient number of follicular cells to provide an appropriate diagnosis and specimens that were not representative of the US image of the lesion (e.g., skeletal muscle and mature adipose tissue, virtually acellular specimen, acellular fibrotic nodule, or blood clot only). The benign category (category II) included all benign thyroidal and non-thyroidal diseases, such as benign follicular nodules (including nodular hyperplasia, follicular adenoma, colloid nodules, and nodules in Graves' disease), Hashimoto's thyroiditis, subacute granulomatous thyroiditis, and non-thyroidal lesions (e.g., parathyroid lesions, benign neurogenic tumor, and benign lymph nodes). Category III were indeterminate lesions, subcategorized as 
indeterminate follicular lesions with nuclear atypia (IIIA) and indeterminate follicular lesions with architectural atypia (IIIB). Category IIIA included follicular proliferative lesions with focal nuclear atypia or atypical follicular cells embedded in fibrotic stroma; category IIIB included microfollicular proliferative lesions lacking a fibrous capsule or adjacent normal thyroid tissue in the specimen. Category IV included follicular neoplasms or cases where there was suspicion of a follicular neoplasm based on the presence of a fibrous capsule and microscopic features that differed from the adjacent thyroid parenchyma. The category for suspicion of malignancy (category $V$ ) included CNB readings with atypical features that were insufficient for definite diagnosis of malignancy. The malignancy category (category VI) referred to specimens that exhibited unequivocal features of cancer. Immunohistochemistry data were not used as the basis for these readings (27).

\section{Reference Standard}

Malignant nodules were diagnosed after surgery or after biopsy with specific pathologic results. Benign nodules were diagnosed either after surgery (with benign findings after FNA and/or CNB that had been repeated at least twice) or after benign findings at CNB with a stable size at 1-year follow-up.

\section{Statistical Analysis}

Diagnostic performance and the incidence of nondiagnostic results, inconclusive results, conclusive results, malignancy, unnecessary surgery, and complications were analyzed. Diagnostic performance was determined by evaluating the diagnostic accuracy, sensitivity, specificity, positive predictive value, and negative predictive value of CNB for the diagnosis of malignancy. The inconclusive result rate was defined as the rate of non-diagnostic results and AUS or FLUS. The conclusive result rate was defined as the combined rate of benign, follicular neoplasms, specimens considered suspicious for a follicular neoplasm or for malignancy, and those having malignancy findings. Unnecessary surgery was defined as two clinical scenarios: 1) when nodules reported as malignant on CNB were confirmed as benign or 2) when nodules reported as follicular neoplasms on CNB were confirmed as adenomatous hyperplasia (29). Major and minor complications were identified according to the Society of Interventional Radiology definitions $(31,32)$. An additional subgroup analysis was performed according to nodule size $(<1 \mathrm{~cm}$ or $\geq 1 \mathrm{~cm}$ ). Results after surgery were compared with those after CNB. Furthermore, a multivariate logistic regression analysis was performed to determine the independent risk factors associated with inconclusive results on CNB. The level of significance was defined as $p<0.05$, and statistical analysis was performed using SPSS 21.0 for Windows software (IBM Corp., Armonk, NY, USA).

\section{RESULTS}

During the study period, a total of 158 thyroid nodules with suspicious features on US were underwent FNA or CNB in our institution. Data from 93 patients (74 female and 19 male) with 102 thyroid nodules who underwent CNB were included in the analysis. CNB was well tolerated in all patients, with no major or minor complications. All samples obtained from CNB were adequate for diagnosis. All nodules were solid; mean size was $1.1 \pm 0.6 \mathrm{~cm}$ (range, $0.3-3.8$ $\mathrm{cm})$. Final diagnoses were obtained for 80 nodules $(78.4 \%)$, including 65 malignant nodules and 15 benign nodules (Table 1). Of the 102 nodules evaluated, $22(21.6 \%)$ had an indeterminate result on biopsy (category III [ $n=7$ ], IIIA [ $n$ $=2]$, IIIB $[n=3], \operatorname{IIIAB}[n=2]$, and category V $[n=2]$ ) or did not have adequate follow-up to confirm the pathology of the nodule $(n=13)$. Malignant nodules were diagnosed

Table 1. CNB Results and Final Diagnosis for Suspicious Thyroid Nodules

\begin{tabular}{|c|c|c|c|c|c|c|}
\hline & \multirow{2}{*}{$\begin{array}{l}\text { Total CNB } \\
(n=102)\end{array}$} & \multicolumn{2}{|c|}{ Final Diagnosis $(n=80)$} & \multirow{2}{*}{$\begin{array}{c}\text { CNB }(\geq 1 \mathrm{~cm}) \\
(n=49)\end{array}$} & \multicolumn{2}{|c|}{ Final Diagnosis $(n=40)$} \\
\hline & & Benign $(n=15)$ & Malignant $(n=65)$ & & Benign $(n=10)$ & Malignant $(n=30)$ \\
\hline Non-diagnostic & 0 & 0 & 0 & 0 & 0 & 0 \\
\hline Benign & $26(25.5)$ & $12(80)$ & $1(1.5)$ & $13(26.5)$ & $7(70)$ & 0 \\
\hline Indeterminate & $13(12.7)$ & $3(20)$ & $3(4.6)$ & $9(18.4)$ & $3(30)$ & $3(10)$ \\
\hline FN or SFN & 0 & 0 & 0 & 0 & 0 & 0 \\
\hline Suspicious for malignancy & $5(4.9)$ & 0 & $3(4.6)$ & $2(4.1)$ & 0 & $2(6.7)$ \\
\hline Malignancy & $58(56.9)$ & 0 & $58(89.2)$ & $25(51)$ & 0 & $25(83.3)$ \\
\hline
\end{tabular}

Data are number of nodules (\%); percentages do not add up to $100 \%$ due to rounding. CNB $=$ core needle biopsy, FN $=$ follicular neoplasm, SFN = suspicious for follicular neoplasm 
after surgery $(n=54)$ or after biopsy $(n=11)$. Benign nodules were diagnosed either after surgery $(n=4)$ or after a benign finding on CNB with a stable size after at least 1 year of follow-up $(n=11)$.

\section{Correlation of CNB Results with Final Diagnosis}

of 80 suspicious thyroid nodules with a final diagnosis, one nodule showed a discordant result between CNB and the pathological examination of the surgical specimen. One nodule initially diagnosed as a benign follicular nodule on CNB was confirmed as a papillary thyroid carcinoma in the pathological examination of the surgical specimen. The nodule was $<1 \mathrm{~cm}$ in size with a maximal diameter of $4 \mathrm{~mm}$ on US. Review of the pathologic slides and US images to determine a possible cause for the discordance in the pathologic results suggested the main reason to be mis-targeting of thyroid nodules during CNB. None of the patients included in the study underwent unnecessary surgery.

\section{Diagnostic Performance of CNB}

The study outcomes of CNB for suspicious thyroid nodules are summarized in Table 2 . The conclusive result rate was $87.3 \%$ ( 89 of $102 ; 95 \%$ confidence interval [CI]: $78.8-92.8)$, whereas the inconclusive result rate was $12.7 \%$ (13 of 102; 95\% CI: 7.2-21.2). The diagnostic accuracy, sensitivity, specificity, positive predictive value, and negative predictive value of CNB for diagnosis of malignancy were $95 \%$ (76 of $80 ; 95 \%$ CI: $87.7-98.6$ ), $93.8 \%$ (61 of 65 ; $95 \%$ CI: $85.0-98.3$ ), $100 \%$ (15 of 15; 95\% CI: $69.8-100.0$ ), $100 \%$ (61 of $61 ; 95 \%$ CI: $91.3-100.0$ ), and $78.9 \%$ (15 of 19; $95 \%$ CI: 54.4-93.9), respectively. Subgroup analysis performed according to nodule size showed no statistically significant difference in the diagnostic performance between nodules $<1 \mathrm{~cm}$ and nodules $\geq 1 \mathrm{~cm}$.

\section{Risk Factors Associated with Inconclusive Results}

The results of the univariate and multivariate logistic regression analyses for the risk factors associated with inconclusive results on CNB are shown in Table 3. The results showed a statistically significant association between inconclusive results and nodule size and needle length.

\section{DISCUSSION}

In this study, we prospectively enrolled consecutive patients who underwent CNB for suspicious thyroid nodules. CNB performed on suspicious thyroid nodules obtained a sufficient sample for diagnosis in all cases, and no patients underwent unnecessary surgery. CNB was associated with high diagnostic values for thyroid cancer, with sensitivity, specificity, and accuracy of $93.8 \%, 100 \%$, and $95 \%$, respectively. These findings suggest that CNB is an effective method for the diagnosis of suspicious thyroid nodules.

Fine needle aspiration is widely accepted as the firstline method for evaluating thyroid nodules. Unfortunately, unsatisfactory or non-diagnostic results present a dilemma for clinicians and radiologists managing thyroid nodules. The Bethesda System for Reporting Thyroid Cytopathology (33) recommends an ideal non-diagnostic rate of $<10 \%$ of all FNAs; however, studies show that up to $21 \%$ of nodules have non-diagnostic results in initial FNA, with the figure being as high as $50-63 \%$ in repeat biopsies (34-37). Previous studies revealed that hypoechogenicity and the presence of calcification on US is related to a high rate of

Table 2. Study Outcomes of CNB for Suspicious Thyroid Nodules

\begin{tabular}{|c|c|c|c|c|c|c|c|}
\hline Study Outcomes & $\begin{array}{c}\text { Incidence, \% } \\
\text { (Total) }\end{array}$ & $95 \% \mathrm{CI}$ & $\begin{array}{c}\text { Incidence, \% } \\
(<1 \mathrm{~cm})\end{array}$ & $95 \%$ CI & $\begin{array}{c}\text { Incidence, } \% \\
(\geq 1 \mathrm{~cm})\end{array}$ & $95 \% \mathrm{CI}$ & $P$ \\
\hline Non-diagnostic & 0 (0 of 102) & $0.0-4.5$ & $0(0$ of 56$)$ & $0.0-8.0$ & $0(0$ of 46$)$ & $0.0-9.6$ & \\
\hline Inconclusive & 12.7 (13 of 102$)$ & $7.2-21.2$ & $7.1(4$ of 56$)$ & $2.3-18.1$ & $19.6(9$ of 46$)$ & $9.9-34.4$ & 0.116 \\
\hline Conclusive & 87.3 (89 of 102) & $78.8-92.8$ & $92.9(52$ of 56$)$ & $81.9-97.7$ & $80.4(37$ of 46$)$ & $65.6-90.1$ & 0.116 \\
\hline Malignancy & 59.8 (61 of 102$)$ & $49.6-69.2$ & $62.5(35$ of 56$)$ & $48.5-74.8$ & $56.5(26$ of 46$)$ & $41.2-70.8$ & 0.682 \\
\hline Diagnostic accuracy & $95(76$ of 80$)$ & $87.7-98.6$ & 97.6 (41 of 42$)$ & $87.4-99.9$ & $92.1(35$ of 38$)$ & $78.6-98.3$ & 0.342 \\
\hline Sensitivity & 93.8 (61 of 65$)$ & $85.0-98.3$ & $97.2(35$ of 36$)$ & $85.5-99.9$ & 89.7 (26 of 29$)$ & $72.6-97.8$ & 0.316 \\
\hline Specificity & $100(15$ of 15$)$ & $69.8-100.0$ & $100(6$ of 6$)$ & $42.1-100.0$ & $100(9$ of 9$)$ & $55.5-100.0$ & 1.0 \\
\hline Positive predictive value & $100(61$ of 61$)$ & $91.3-100.0$ & $100(35$ of 35$)$ & $85.5-100.0$ & $100(26$ of 26$)$ & $81.0-100.0$ & 1.0 \\
\hline Negative predictive value & 78.9 (15 of 19) & $54.4-93.9$ & 85.7 (6 of 7) & $42.1-99.6$ & 75 (9 of 12) & $42.8-94.5$ & 1.0 \\
\hline Unnecessary surgery & $0(0$ of 57$)$ & $0.0-7.9$ & $0(0$ of 30$)$ & $0.0-14.1$ & 0 (0 of 27) & $0.0-15.5$ & 1.0 \\
\hline
\end{tabular}

$\mathrm{CI}=$ confidence interval 
Table 3. Results of Univariate and Multivariate Analysis to Determine Risk Factors Associated with Inconclusive Results

\begin{tabular}{|c|c|c|c|c|c|}
\hline \multicolumn{2}{|l|}{ Variables } & \multirow{2}{*}{$\begin{array}{c}\text { Conclusive }(n=89) \\
51 \pm 14.5\end{array}$} & \multirow{2}{*}{$\frac{\text { Inconclusive }(n=13)}{57 \pm 10.8}$} & \multirow{2}{*}{$\frac{P \text {, Univariate }}{0.218}$} & \multirow[t]{2}{*}{$P$, Multivariate } \\
\hline Age, years & $52 \pm 14.2$ & & & & \\
\hline Sex (male:female) & $20: 82$ & $16: 73$ & $4: 9$ & 0.285 & \\
\hline \multirow{3}{*}{ Nodule size, $\mathrm{cm}$} & $1.1 \pm 0.6$ & $1.0 \pm 0.5$ & $1.5 \pm 0.9$ & 0.018 & 0.002 \\
\hline & $<1.0, \mathrm{n}(\%)$ & $49(55.1)$ & $4(30.8)$ & 0.071 & \\
\hline & $\geq 1.0, \mathrm{n}(\%)$ & $40(44.9)$ & $9(69.2)$ & & \\
\hline Composition, n (\%) & Solid & $89(100)$ & $13(100)$ & & \\
\hline \multirow{3}{*}{ Shape, n (\%) } & Ovoid-to-round & $55(61.8)$ & $11(84.6)$ & 0.221 & \\
\hline & Taller than wide & $33(37.1)$ & $2(15.4)$ & & \\
\hline & Irregular & $1(1.1)$ & $0(0)$ & & \\
\hline \multirow{3}{*}{ Margin, n (\%) } & Smooth & $8(9.0)$ & $2(15.4)$ & 0.391 & \\
\hline & Spiculated & $65(73.0)$ & $7(53.8)$ & & \\
\hline & Ill-defined & $16(18.0)$ & $4(30.8)$ & & \\
\hline \multirow{3}{*}{ Echogenicity, n (\%) } & Isohyperechoic & $4(4.5)$ & $2(15.4)$ & 0.317 & \\
\hline & Hypoechoic & $45(50.6)$ & $7(53.8)$ & & \\
\hline & Markedly hypoechoic & $40(44.9)$ & $4(30.8)$ & & \\
\hline \multirow{3}{*}{ Calcification, n (\%) } & None & $24(27.0)$ & $4(30.8)$ & 0.319 & \\
\hline & Microcalcifications & $57(64.0)$ & $9(69.2)$ & & \\
\hline & Macrocalcifications & $8(9.0)$ & $0(0)$ & & \\
\hline \multirow{2}{*}{ Number of biopsies, $\mathrm{n}(\%)$} & 1 & $83(93.3)$ & $12(92.3)$ & 0.899 & \\
\hline & 2 & $6(6.7)$ & $1(7.7)$ & & \\
\hline \multirow{2}{*}{ Length of needle, $\mathrm{n}(\%)$} & $1.1 \mathrm{~cm}$ & $81(91.0)$ & $12(92.3)$ & 0.878 & 0.049 \\
\hline & $1.6 \mathrm{~cm}$ & $8(9.0)$ & $1(7.7)$ & & \\
\hline \multirow{2}{*}{ Operator, n (\%) } & Staff & $58(65.2)$ & $7(53.8)$ & 0.193 & \\
\hline & Fellow & $31(34.8)$ & $6(46.2)$ & & \\
\hline
\end{tabular}

non-diagnostic results on FNA $(38,39)$. Hypoechogenicity is related to an increased cell density (38) and calcification (especially macrocalcification), therefore making it difficult to penetrate with a fine needle and leading to the failure to obtain an adequate cell sample (39). These factors mean that a considerable proportion of suspicious thyroid nodules assessed by FNA result in an uncertain diagnosis. In this study, CNB showed no non-diagnostic results for suspicious thyroid nodules, and the inconclusive result was not influenced by US characteristics. Therefore, this study suggests that the diagnostic value of CNB is independent and not reliant on US characteristics.

For suspicious thyroid nodules with initially benign cytological results, false-negative specimens are a particular concern. One study showed that $28(32.9 \%)$ of 85 suspicious thyroid nodules with benign FNA results were histologically upgraded according to CNB specimens and $27(31.8 \%)$ were finally confirmed as malignant (11). In the present study, among 13 patients with a benign result on CNB, nodules of only one patient were subsequently confirmed as malignant (false-negative rate: $7.8 \%$ ), the reason for this being mistargeting of the thyroid nodules.
The relatively large tissue sample obtained by CNB is a wellacknowledged diagnostic strength. In addition, monitoring the procedure using real-time US and the ability to visually inspect the adequacy of the tissue core (18) also leads to a lower false-negative rate with CNB. Therefore, clinicians should carefully consider re-biopsy or diagnostic surgical procedures for patients with US-CNB pathology discordant thyroid nodules because the risk of malignancy is relatively low. However, Chung et al. (27) recommended re-biopsy for US-CNB pathology discordant thyroid nodules with more than two suspicious US features because the malignancy risk is significantly higher than in nodules with one suspicious US feature.

The false-positive rate of FNA results in thyroid cancer has been reported as 2-10\% (40-42), with Hashimoto's thyroiditis being the most common cause of false-positive cytology. Misclassification of follicular and Hürthle cell adenomas as papillary carcinomas accounts for additional errors (43). For CNB, no false-positive results were noted in the present study.

The inconclusive result rate associated with CNB was relatively high $(12.7 \%)$. This is, however, lower than the 
inconclusive result rate reported with FNA in previous studies (10-33.6\%) (3-6). All of the inconclusive CNB results in the present study were indeterminate (category III). On multivariate logistic regression analysis, the inconclusive results were related to nodule size (larger size) and length of needle $(1.1 \mathrm{~cm})$. According to the pathologic reporting system of thyroid CNBs, if a fibrous capsule or adjacent normal thyroid tissue is not identified in a CNB specimen that shows a predominantly microfollicular or trabecular growth pattern, it is reasonable to classify the lesion as diagnostic category III because the presence or absence of a fibrous capsule cannot be determined (30). Therefore, in large nodules, biopsy using a short-length needle is likely to result in a higher inconclusive result rate due to limited evaluation of the capsule of the nodule. If biopsy is performed on a nodule suspected of having a capsule, it may be helpful to obtain a sample that includes the nodule, nodule capsule, and adjacent normal glandular tissue with a long-length needle (44).

This study has several limitations. First, we used a relatively small sample size and a control group was not included in the study. Further investigation with a larger sample size and direct comparison between CNB and FNA will be required to verify the results of the study. Second, among the 15 benign nodules, 11 were confirmed by a benign result on CNB and size stability by US at 1-year follow-up. As thyroid cancers can grow very slowly, this follow-up period may not be sufficient to exclude a slowgrowing malignancy. However, the definition of a benign nodule was based on previous publications $(11,13,27$, 29). Finally, this study was conducted in a single specialist center and different results may have been obtained in community hospitals with less experienced operators. However, the difference in operator experience did not affect the inconclusive result rate in this study.

In conclusion, this study demonstrates that CNB obtained sufficient samples for diagnosis in all cases and resulted in high diagnostic values for evaluating suspicious thyroid nodules. CNB was associated with a high rate of conclusive results, and no patients underwent unnecessary surgery based on the CNB results. These findings indicated that CNB is a promising diagnostic tool for suspicious thyroid nodules.

\section{Conflicts of Interest}

The authors have no financial conflicts of interest.
ORCID

Jung Hwan Baek

https://orcid.org/0000-0003-0480-4754

Sae Rom Chung

https://orcid.org/0000-0003-4219-7166

\section{REFERENCES}

1. Haugen BR, Alexander EK, Bible KC, Doherty GM, Mandel SJ, Nikiforov YE, et al. 2015 American Thyroid Association management guidelines for adult patients with thyroid nodules and differentiated thyroid cancer: the American Thyroid Association guidelines task force on thyroid nodules and differentiated thyroid cancer. Thyroid 2016;26:1-133

2. Shin JH, Baek JH, Chung J, Ha EJ, Kim JH, Lee YH, et al.; Korean Society of Thyroid Radiology (KSThR) and Korean Society of Radiology. Ultrasonography diagnosis and imagingbased management of thyroid nodules: revised Korean Society of Thyroid Radiology Consensus statement and recommendations. Korean J Radiol 2016;17:370-395

3. Gharib H, Papini E, Paschke R, Duick DS, Valcavi R, Hegedüs $L$, et al.; AACE/AME/ETA Task Force on Thyroid Nodules. American Association of Clinical Endocrinologists, Associazione Medici Endocrinologi, and EuropeanThyroid Association medical guidelines for clinical practice for the diagnosis and management of thyroid nodules. Endocr Pract 2010;16 Suppl 1:1-43

4. Nayar R, Ivanovic M. The indeterminate thyroid fine-needle aspiration: experience from an academic center using terminology similar to that proposed in the 2007 National Cancer Institute Thyroid Fine Needle Aspiration state of the science conference. Cancer 2009;117:195-202

5. Yassa L, Cibas ES, Benson CB, Frates MC, Doubilet PM, Gawande AA, et al. Long-term assessment of a multidisciplinary approach to thyroid nodule diagnostic evaluation. Cancer 2007;111:508-516

6. Degirmenci B, Haktanir A, Albayrak R, Acar M, Sahin DA, Sahin 0 , et al. Sonographically guided fine-needle biopsy of thyroid nodules: the effects of nodule characteristics, sampling technique, and needle size on the adequacy of cytological material. Clin Radiol 2007;62:798-803

7. Bongiovanni M, Spitale A, Faquin WC, Mazzucchelli L, Baloch ZW. The Bethesda system for reporting thyroid cytopathology: a meta-analysis. Acta Cytol 2012;56:333-339

8. Chehade JM, Silverberg AB, Kim J, Case C, Mooradian AD. Role of repeated fine-needle aspiration of thyroid nodules with benign cytologic features. Endocr Pract 2001;7:237-243

9. Kim SY, Han KH, Moon HJ, Kwak JY, Chung WY, Kim EK. Thyroid nodules with benign findings at cytologic examination: results of long-term follow-up with US. Radiology 2014;271:272-281

10. Orlandi A, Puscar A, Capriata E, Fideleff H. Repeated fineneedle aspiration of the thyroid in benign nodular thyroid 
disease: critical evaluation of long-term follow-up. Thyroid 2005;15:274-278

11. Ha EJ, Baek JH, Lee JH, Song DE, Kim JK, Shong YK, et al. Sonographically suspicious thyroid nodules with initially benign cytologic results: the role of a core needle biopsy. Thyroid 2013;23:703-708

12. Kwak JY, Kim EK, Kim HJ, Kim MJ, Son EJ, Moon HJ. How to combine ultrasound and cytological information in decision making about thyroid nodules. Eur Radiol 2009;19:1923-1931

13. Kwak JY, Koo H, Youk JH, Kim MJ, Moon HJ, Son EJ, et al. Value of US correlation of a thyroid nodule with initially benign cytologic results. Radiology 2010;254:292-300

14. Chernyavsky VS, Shanker BA, Davidov T, Crystal JS, Eng 0 , Ibrahim $\mathrm{K}$, et al. Is one benign fine needle aspiration enough? Ann Surg Oncol 2012;19:1472-1476

15. Shin JH, Han BK, Ko K, Choe YH, Oh YL. Value of repeat ultrasound-guided fine-needle aspiration in nodules with benign cytological diagnosis. Acta Radiol 2006;47:469-473

16. Hwang SH, Sung JM, Kim EK, Moon HJ, Kwak JY. Imagingcytology correlation of thyroid nodules with initially benign cytology. Int J Endocrinol 2014;2014:491508

17. Moon HJ, Kim EK, Kwak JY. Malignancy risk stratification in thyroid nodules with benign results on cytology: combination of thyroid imaging reporting and data system and Bethesda system. Ann Surg Oncol 2014;21:1898-1903

18. Na DG, Baek JH, Jung SL, Kim JH, Sung JY, Kim KS, et al.; Korean Society of Thyroid Radiology (KSThR) and Korean Society of Radiology. Core needle biopsy of the thyroid: 2016 Consensus Statement and Recommendations from Korean Society of Thyroid Radiology. Korean J Radiol 2017;18:217237

19. Baek JH. Current status of core needle biopsy of the thyroid. Ultrasonography 2017;36:83-85

20. Jung CK, Baek JH. Recent advances in core needle biopsy for thyroid nodules. Endocrinol Metab (Seoul) 2017;32:407-412

21. Screaton NJ, Berman LH, Grant JW. US-guided core-needle biopsy of the thyroid gland. Radiology 2003;226:827-832

22. Choi SH, Baek JH, Lee JH, Choi YJ, Hong MJ, Song DE, et al. Thyroid nodules with initially non-diagnostic, fine-needle aspiration results: comparison of core-needle biopsy and repeated fine-needle aspiration. Eur Radiol 2014;24:28192826

23. Yeon JS, Baek JH, Lim HK, Ha EJ, Kim JK, Song DE, et al. Thyroid nodules with initially nondiagnostic cytologic results: the role of core-needle biopsy. Radiology 2013;268:274-280

24. Choi YJ, Baek JH, Ha EJ, Lim HK, Lee JH, Kim JK, et al. Differences in risk of malignancy and management recommendations in subcategories of thyroid nodules with atypia of undetermined significance or follicular lesion of undetermined significance: the role of ultrasound-guided core-needle biopsy. Thyroid 2014;24:494-501

25. Sung JY, Na DG, Kim KS, Yoo H, Lee H, Kim JH, et al. Diagnostic accuracy of fine-needle aspiration versus coreneedle biopsy for the diagnosis of thyroid malignancy in a clinical cohort. Eur Radiol 2012;22:1564-1572

26. Na DG, Kim JH, Sung JY, Baek JH, Jung KC, Lee H, et al. Core-needle biopsy is more useful than repeat fine-needle aspiration in thyroid nodules read as nondiagnostic or atypia of undetermined significance by the Bethesda system for reporting thyroid cytopathology. Thyroid 2012;22:468-475

27. Chung SR, Baek JH, Park HS, Choi YJ, Sung TY, Song DE, et al. Ultrasound-pathology discordant nodules on core-needle biopsy: malignancy risk and management strategy. Thyroid 2017;27:707-713

28. Moon WJ, Jung SL, Lee JH, Na DG, Baek JH, Lee YH, et al.; Thyroid Study Group, Korean Society of Neuro- and Head and Neck Radiology. Benign and malignant thyroid nodules: US differentiation--multicenter retrospective study. Radiology 2008;247:762-770

29. Suh CH, Baek JH, Lee JH, Choi YJ, Kim JK, Sung TY, et al. The role of core-needle biopsy as a first-line diagnostic tool for initially detected thyroid nodules. Thyroid 2016;26:395-403

30. Jung CK, Min HS, Park HJ, Song DE, Kim JH, Park SY, et al. Pathology reporting of thyroid core needle biopsy: a proposal of the Korean Endocrine Pathology Thyroid Core Needle Biopsy Study Group. J Pathol Transl Med 2015;49:288-299

31. Lewis CA, Allen TE, Burke DR, Cardella JF, Citron SJ, Cole $P E$, et al. Quality improvement guidelines for central venous access. The standards of practice committee of the Society of Cardiovascular \& Interventional Radiology. J Vasc Interv Radiol 1997;8:475-479

32. Burke DR, Lewis CA, Cardella JF, Citron SJ, Drooz AT, Haskal ZJ, et al.; Society of Interventional Radiology Standards of Practice Committee. Quality improvement guidelines for percutaneous transhepatic cholangiography and biliary drainage. J Vasc Interv Radiol 2003;14(9 Pt 2):S243-S246

33. Cibas ES, Ali SZ. The Bethesda system for reporting thyroid cytopathology. Thyroid 2009;19:1159-1165

34. Alexander EK, Heering JP, Benson CB, Frates MC, Doubilet PM, Cibas ES, et al. Assessment of nondiagnostic ultrasoundguided fine needle aspirations of thyroid nodules. J Clin Endocrinol Metab 2002;87:4924-4927

35. Baloch Z, LiVolsi VA, Jain P, Jain R, Aljada I, Mandel S, et al. Role of repeat fine-needle aspiration biopsy (FNAB) in the management of thyroid nodules. Diagn Cytopathol 2003;29:203-206

36. Richards ML, Bohnenblust E, Sirinek K, Bingener J. Nondiagnostic thyroid fine-needle aspiration biopsies are no longer a dilemma. Am J Surg 2008;196:398-402

37. Baier ND, Hahn PF, Gervais DA, Samir A, Halpern EF, Mueller $P R$, et al. Fine-needle aspiration biopsy of thyroid nodules: experience in a cohort of 944 patients. AJR Am J Roentgenol 2009;193:1175-1179

38. Woo SH, Kim KH, Kim RB. Thyroid nodules with repeat nondiagnostic cytologic results: the role of clinical and ultrasonographic findings. World J Surg 2015;39:1721-1727

39. Choi SH, Han KH, Yoon JH, Moon HJ, Son EJ, Youk JH, et al. Factors affecting inadequate sampling of ultrasound- 
guided fine-needle aspiration biopsy of thyroid nodules. Clin Endocrinol (Oxf) 2011;74:776-782

40. Yoon JH, Kwak JY, Moon HJ, Kim MJ, Kim EK. The diagnostic accuracy of ultrasound-guided fine-needle aspiration biopsy and the sonographic differences between benign and malignant thyroid nodules $3 \mathrm{~cm}$ or larger. Thyroid 2011;21:993-1000

41. Lew JI, Snyder RA, Sanchez YM, Solorzano CC. Fine needle aspiration of the thyroid: correlation with final histopathology in a surgical series of 797 patients. J Am Coll Surg 2011;213:188-194; discussion 194-195

42. Sclabas GM, Staerkel GA, Shapiro SE, Fornage BD, Sherman SI, Vassillopoulou-Sellin $\mathrm{R}$, et al. Fine-needle aspiration of the thyroid and correlation with histopathology in a contemporary series of 240 patients. Am J Surg 2003;186:702-709;

discussion 709-710

43. Dean DS, Gharib H. Fine-needle aspiration biopsy of the thyroid gland. In: De Groot LJ, Chrousos G, Dungan K, Feingold KR, Grossman A, Hershman JM, et al., eds. Endotext [Internet]. South Dartmouth, MA: MDText.com, Inc., 2015

44. Na DG, Min HS, Lee H, Won JK, Seo HB, Kim JH. Role of core needle biopsy in the management of atypia/follicular lesion of undetermined significance thyroid nodules: comparison with repeat fine-needle aspiration in subcategory nodules. Eur Thyroid J 2015;4:189-196 